\title{
Retrospective Study of histomorphological spectrum of ovarian tumours in GCS Medical College, Hospital and Research Center, Ahmedabad
}

\author{
Rangaliya K. ${ }^{1}$, Purohit A. ${ }^{2}$, Patel S.M. ${ }^{3}$ \\ ${ }^{1}$ Dr. Kalpesh Rangaliya, Resident, ${ }^{2}$ Dr. Asha Purohit, Associate Professor, ${ }^{3}$ Dr. Shantibhai M. Patel, HOD \& Professor, \\ all authors are affiliated with Department of Pathology, GCS Medical College Hospital and Research Center.
}

Corresponding Author: Dr. Asha Purohit, Associate Professor, Department of Pathology, GCS Medical College Hospital and Research Center. E-mail: ashapurohit54@gmail.com

\begin{abstract}
Background and objectives: Ovarian tumours accounts for $30 \%$ of female genital cancers and have become increasingly important not only because of the large variety of neoplastic entities but also because they have gradually increased the mortality rate. Ovarian neoplasm remains asymptomatic until there is massive ovarian enlargement which causes compression of pelvic structures, ascites, abdominal distension or distant metastasis. Thus present study was undertaken to analyze the frequency of various histomorphological spectrum, histological subtypes and age distribution pattern of ovarian tumours. Methods: Retrospective study was carried during period of $1^{\text {st }}$ June 2017 to $30^{\text {st }}$ November 2018, 57 cases of ovarian neoplastic lesions were taken from the records of the department. Results: A total number of 57 cases were studied. Among these, 41 cases $(71.92 \%)$ were of benign tumours, 2 cases $(3.50 \%)$ were of borderline tumours and 14 cases $(24.56 \%)$ were of malignant tumours. Serous cystadenomas $(26 / 41)(63.41 \%)$ were the commonest benign tumours followed by Mucinous cystadenomas (6/41)(14.63\%). Among the malignant surface epithelial tumours serous cystadenocarcinomas (6/14) $(42.86 \%)$ were most common followed by Mucinous cystadenocarcinomas $(3 / 14)$ (21.43\%). Germ cell neoplasms constituted $19.30 \%$ of all ovarian neoplasms. Conclusion: Ovarian tumours cannot easily be diagnosed by clinical symptoms only, histological examination is therefore necessary for diagnosis and grading of ovarian tumours. Females with family history of endometrial and breast carcinoma has got increased incidence of ovarian carcinoma and ovary is also common site for metastasis from other primary gynecological as well as non gynecological carcinomas e.g. endometrium, stomach and breast. Hence present study was carried out in the department of pathology for early diagnosis of ovarian carcinomas, their histological sub typing and their age distribution pattern.
\end{abstract}

Keywords: Ovarian tumours, Benign, Borderline, Malignant

\section{Introduction}

Ovarian tumours are common forms of neoplasia in women and accounts for $30 \%$ of female genital cancers [1]. The earliest report of the ovarian neoplasms has been reported by shushruta in his book 'shushruta and ayurveda'. Incidence and prevalence of ovarian cancer vary in different geographical areas of the country.

Indian trend analysis reveals a steady increase in the age with standardized incidence rate of ovarian cancer ranging from $0.26 \%$ to $2.44 \%$ per year in different areas registries. It has worst prognosis among all gynecological malignancies and has highest case fatality rate. Overall 5 -year survival is $45 \%$, primarily because of the late stage at diagnosis of the disease [2].

Manuscript received: $4^{\text {th }}$ January 2019

Reviewed: $14^{\text {th }}$ January 2019

Author Corrected: $18^{\text {th }}$ January 2019

Accepted for Publication: $21^{\text {st }}$ January 2019
Ovarian neoplasms have become increasingly important not only because of the large variety of neoplastic entities but also because they have gradually increased the mortality rate in female genital cancers.

Most ovarian tumours cannot be confidently distinguished from one another on the basis of their clinical or gross characteristics alone. These features provide important diagnostic clues in some cases, however in such cases both the clinician and the pathologist should share their valuable information in establishing a correct diagnosis [3].

There is increased risk of developing ovarian, breast, or endometrial (uterine) cancer, if the person inherits a specific type of genetic abnormality called a $B R C A 1$ or BRCA2mutation [4]. 
Family history of Lynch syndrome (hereditary nonpolyposis colorectal cancer [HNPCC]) which is an autosomal dominant genetic condition has a high risk of colon cancer as well as other cancers including endometrial cancer (second most common), ovary, stomach, small intestine, hepatobiliary tract, upper urinary tract, brain, and skin. Women in families with this trait have up to a 60 percent chance of developing endometrial cancer and 10 to 12 percent chance of developing ovarian cancer [5].

Ovary is common site of metastases from other primary malignancies, and $5-30 \%$ of ovarian cancers are metastatic malignancies. Metastatic ovarian carcinoma accounted for $15.7 \%$ of all ovarian malignancies. The primary sites of non gynecologic tumours are the colon $(30 \%)$, stomach $(16 \%)$, appendix (13\%), breast $(13 \%)$, pancreas $(12 \%)$, biliary tract $(15 \%)$, and liver (4\%).

Gynecologic primary sites are the uterine cervix $(4 \%)$ and the uterine body (23\%). In study primary malignancies were detected first in 66 patients $(44 \%)$ and simultaneously with ovarian metastasis in 53 patients (35.3\%). An ovarian mass was the first manifestation of disease in $20.6 \%$ of the cases. Patients ranged in age from 26 to 72 years (mean, 51). Krukenberg tumours were found in 35 patients $(23 \%)$ [6].

Cytoreductive surgery in metastatic ovarian cancer may be beneficial for the initial diagnosis or symptom relief, but the survival benefit of surgery remains controversial [7]. Cytoreductive surgery for ovarian cancer is generally performed at the time of diagnosis, when it is referred to as primary cytoreduction, it is also performed during primary chemotherapy (interval cytoreduction) and after disease recurrence (secondary cytoreduction). [8].

Evaluation of PAX8 and h-caldesmon expression can successfully distinguish mesothelioma from serous ovarian tumours [9].

Evaluation of ovarian enlargement is best accomplished by ultrasound. CA 125 most frequently used biomarker for ovarian cancerishigher than normal in approximately 80 percent of women with ovarian cancer. CA 125 is commonly used to monitor women with ovarian cancer; however benign situations like endometriosis and infection can also elevate CA 125 level. Other diagnostic tests for epithelial ovarian cancer include human epididymis protein (HE4), the OVA1 panel, and the Risk of Malignancy Algorithm (ROMA). [10].

\section{Original Research Article}

Serous tumours make up about one-fourth of all ovarian tumours. Most cases occur in adults and approximately $30-50 \%$ tumours are bilateral. Both low-grade serous carcinoma and atypical proliferative serous tumor (APST)/non-invasive MPSC (micro papillary serous borderline tumor) are characterized by mutations of the $K R A S, B R A F$, orERBB2 genes, in which approxi-mately two thirds of tumours have a mutation of 1 of these genes. However, KRAS and BRAF are much more commonly mutated than ERBB2 [11].

Mucinous neoplasms are less common than serous neoplasms and are bilateral in only $10-20 \%$ cases. Microscopically ovarian mucinous tumours particularly those of a borderline nature, have been divided into two major types 1) Intestinal type -according to the World Health Organization criteria for the diagnosis of intestinal type mucinous borderline tumor include the following elements: tumors contain cystic spaces lined by gastrointestinal type mucinous epithelium with stratification and may form filiform papillae with at least minimal stromal support; nuclei are slightly larger than those seen in cystadenomas; mitotic activity is present; goblet cells and sometimes Paneth cells are present, but stromal invasion is absent [12] and 2) Endocervical type-, It is a rare ovarian tumor with low or borderline malignant potential. The causal factors for ovarian mucinous borderline tumour of endocervical type are unknown though genetic mutations have been reported in some cases.

Distinction of borderline tumours is not always easy (particularly with the carcinomas, in which it is rarely attempted), andis backed by ultra structural, histochemical, and immunohistochemicaldata. Immunohistochemistry may also be useful in determining primary versus metastatic mucinous ovarian carcinoma, primary mucinous ovarian carcinoma often demonstrate CK7 and CK20 positivity, while colorectal primaries are usually positive only for CK20 [13].

The secondary development of malignancy is a rare but well-known phenomenon in patients with ovarian teratomas.Squamous cell carcinoma accounts for $80 \%$ of secondary malignant transformations of ovarian teratomas [14].

\section{Material and Methods}

The present study was based on histopathological evaluation of 57 cases of ovarian neoplastic lesions.

Place of study: Department of Histopathology, G.C.S. Medical College Hospital and Research Center, Ahmedabad. 
Type of study: Retrospective study was carried during period of $1^{\text {st }}$ June 2017 to $30^{\text {st }}$ November 2018.

Sampling Methods: Cases were taken from the records of the department, blocks were retrieved and relevant clinical history was noted from the requisition forms.

Inclusion criteria: Present study included all benign and malignant ovarian tumours.

Exclusion criteria: 1) Paraffin blocks made from frozen specimen. 2) Reports which were inconclusive

\section{Original Research Article}

Gross specimens received were fixed in 10 percent formalin for 24 hours and multiple sections from each specimen were taken to include the representative area for histological examination. Sections were processed by routine paraffin method, blocks were cut at five micron thickness and the sections were stained with conventional Haematoxylin and Eosin (H\&E) stain.

Classification: The lesions were then classified and studied according to WHO Classification of ovarian tumors. [15].

Statistical methods: Microsoft offices excel 2007.

\section{Results}

A total number of 57 cases were studied. Among these, 41 cases $(71.92 \%)$ were benign, 2 cases $(3.50 \%)$ were borderline and 14 cases $(24.56 \%)$ were malignant tumours.

Benign neoplasms were most commonly seen in 2nd to 5 th decade, whereas malignant neoplasms were commonly seen in 5 th decade (Table - 1, 2). Out of 43 surface epithelial tumors $78.04 \%$ were benign, $21.95 \%$ were malignant and $0.02 \%$ were border line neoplasms as per Table- 3

Serous cystadenomas $(63.41 \%)$ were the commonest benign tumour followed by Mucinous cystadenomas (14.63\%) as per Table - 1 .

Among the malignant surface epithelial tumours, serous cystadenocarcinoma (14.63\%) were most common followed by Mucinous cystadenocarcinomas (0.07\%). Germ cell neoplasms constituted $19.30 \%$ of all ovarian neoplasms. Most of the germ cell neoplasms (81.81\%) were benign and reported as mature cystic teratomas or dermoid cysts a tumours composed of tissues representing at least two but usually all three embryonic layers. Two cases were reported as Dysgerminoma. $0.02 \%$ cases were classified as Sex cord stromal tumours.

Table1: Frequency of individual benign tumours in different age groups.

\begin{tabular}{|c|c|c|c|c|c|c|c|c|}
\hline \multirow[t]{2}{*}{ Histological type } & \multicolumn{8}{|c|}{ Age in years } \\
\hline & 0-20 & 21-30 & $31-40$ & $41-50$ & $51-60$ & $61-70$ & $>70$ & Total \\
\hline Serous cystadenoma & & 6 & 8 & 8 & 4 & & 1 & 26 \\
\hline Mucinous cystadenoma & & 3 & 3 & & & & & 06 \\
\hline Benign mature teratoma & 1 & 3 & 1 & 1 & 2 & 1 & & 09 \\
\hline Borderline tumors & & 1 & & 1 , & & & & 02 \\
\hline Total & 01 & 13 & 12 & 09 & 06 & 01 & 01 & 43 \\
\hline
\end{tabular}

Table-2: Frequency of individual malignant tumours in different age groups.

\begin{tabular}{|l|c|c|c|c|c|c|c|c|}
\hline \multirow{2}{*}{ Histological type } & \multicolumn{7}{|c|}{ Age in years } & Total \\
\cline { 2 - 9 } & $\mathbf{0 - 2 0}$ & $\mathbf{2 1 - 3 0}$ & $\mathbf{3 1 - 4 0}$ & $\mathbf{4 1 - 5 0}$ & $\mathbf{5 1 - 6 0}$ & $\mathbf{6 1 - 7 0}$ & $>\mathbf{7 0}$ & 06 \\
\hline $\begin{array}{l}\text { Serous cystadeno- } \\
\text { carcinoma }\end{array}$ & & & 1 & 1 & 4 & & & 03 \\
\hline $\begin{array}{l}\text { Mucinous cystadeno- } \\
\text { carcinoma }\end{array}$ & & 1 & & 1 & 1 & & & 03 \\
\hline Granulosa cell tumor & & 1 & 1 & & & & 1 & 02 \\
\hline Dysgerminoma & & 2 & & & & & & $\mathbf{0 1}$ \\
\hline Total & $\mathbf{0 0}$ & $\mathbf{0 4}$ & $\mathbf{0 2}$ & $\mathbf{0 2}$ & $\mathbf{0 5}$ & $\mathbf{0 0}$ & $\mathbf{0 1}$ \\
\hline
\end{tabular}




\section{Original Research Article}

Table-3: Distribution of ovarian neoplasms according to histological type

\begin{tabular}{|c|c|c|}
\hline Type & No. & \% \\
\hline Surface epithelial tumours & 43 & 75.43 \\
\hline Germ cell tumours & 11 & 19.30 \\
\hline Sex cord stromal tumours & 03 & 0.05 \\
\hline
\end{tabular}

Table-4: Frequency of benign, malignant and borderline ovarian neoplasms in various studies.

\begin{tabular}{|c|c|c|c|}
\hline Type of Tumor & Ahmad, et al. & Pilli, et al. & Present study \\
\hline Benign & 59.18 & 75.2 & $71.92(41 / 57)$ \\
\hline Borderline & 0.2 & 2.8 & $3.50(2 / 57)$ \\
\hline
\end{tabular}

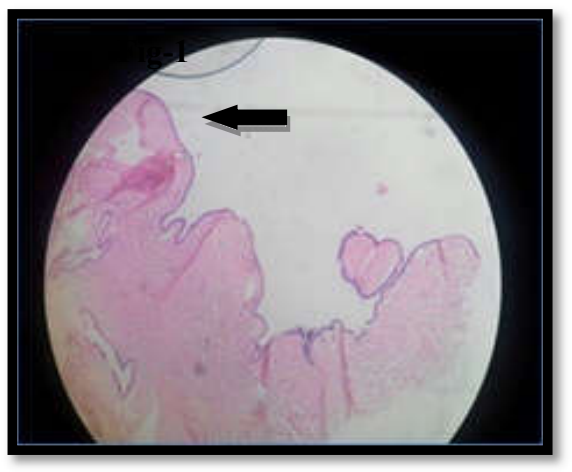

Fig-1

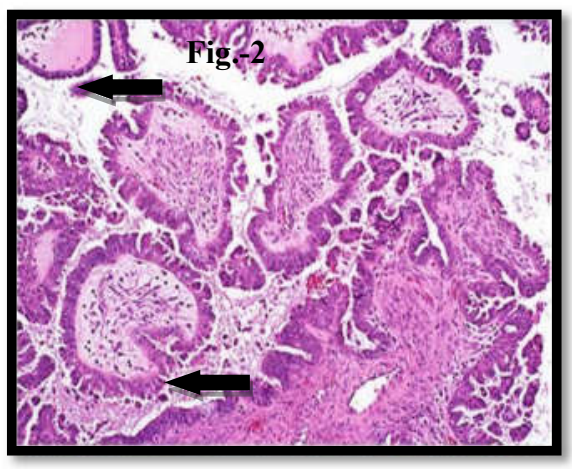

Fig.-2

Figure-1: Serous cystadenoma of the ovary: [H\&E10 x] shows cuboidal to columnar lining epithelium.

Figure-2: Serous cystadenocarcinoma of the ovary: [H\&E40 $x]$ shows papillary growth with hyper chromatic nuclei.

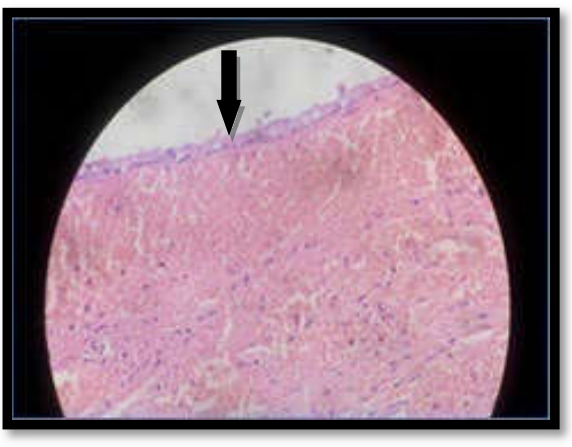

Fig.-3

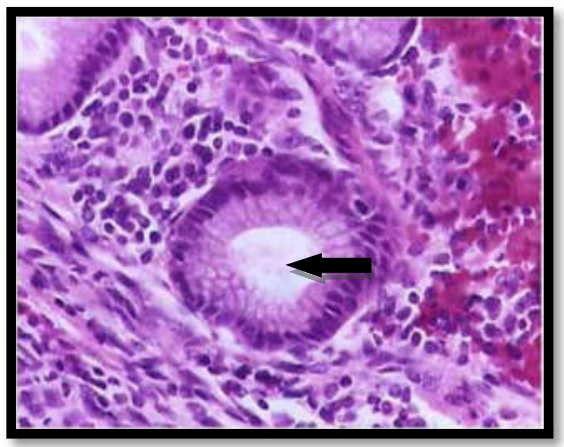

Fig.-4

Figure-3: Mucinous cystadenoma of the ovary. [H\&E10 x] shows tall columnar mucin producing epithelium.

Figure-4: Mucinous cystadenocarcinoma: [H\&E $10 \mathrm{x}$ ] fig shows papillae and glands lined by highly atypical cells with frequent mitoses. The underlying stroma penetrated by nests of malignant cells.

\section{Discussion}

Most ovarian tumours cannot be confidently distinguished from one another on the basis of their clinical or gross characteristics alone. This feature provide important diagnostic clues in some casesand in such cases both the clinician and the pathologist should share their valuable information in establishing a correct diagnosis. Benign ovarian cysts are the commonest ovarian neoplasm constituting about $80 \%$ of ovarian tumours and mostly occur in young women between the ages of 20-40 years. Borderline tumours occur at slightly older ages and are categorized by abnormal cells that form in the tissue covering the ovary and usually affect women aged between 20 - 40 years whereas the malignant tumours are common in older women between the ages of 40-65 years. Though certain investigations like peritoneal fluid cytology, 


\section{Original Research Article}

estimation of serum lactate dehydrogenase, fibrin degradation products and immunological tests have been reported to be of some help in predicting the nature of the pathology, it is generally impossible to diagnose the nature of the ovarian tumour preoperatively just by clinical examination and exploration. Hence one has to depend on the microscopic appearance of the tumour for further management of the ovarian tumours [16].

In present study of 41 cases $(71.92 \%)$ were benign, 14 cases $(24.56 \%)$ were malignant and 2 cases $(2.1 \%)$ were borderline tumours whichis almost similar to the data from western countries where $70.0-80.0 \%$ of ovarian tumours were benign.

One of the studiesin India by Pilli et al observed similar results with $75.20 \%$ of cases, whereas study in Pakistan by Ahmed et al observed only $59.18 \%$ of benigncases. Table- 4

Benign neoplasms were most commonly seen in 3rd to 5th decade, whereas malignant neoplasms were commonly seen in 5th decade. Similar results were also observed in otherstudies, with peak incidence of ovarian tumours in the same age group [18].

Among the major histological classes, the commonest type of ovarian neoplasm seen in present study was surface epithelial tumours $(75.43 \%)$. However, a higher incidence of epithelial tumours $(90 \%)$ was documented in study done byGuppey et al [17].

Serous cyst adenocarcinomas are the most common primary epithelial ovarian malignancy in this study. Tumours in borderline category are characterized by epithelial proliferation greater than that of the benign tumour but an absence of destructive invasive stroma. In this study only $2.1 \%(2 / 57)$ tumours were classified as borderline tumours or tumours of low malignant potential.

The data available from present study can help in recognizing the pattern of ovarian tumours. Whether the malignant tumour arises de novo or benign tumour transforms into malignant is the subject of ongoing debate and research. Germ cell tumours comprised $19.30 \%$ of all ovarian neoplasms. This is similar to findings reported by Tyagi, et al. (23.58\%) [19].

$81.81 \%$ of ovarian germ cell tumours are mature cystic teratomas in the western world which was also observed in present study. The frequency of sex - cord - stromal tumours (SCST) in present study was $0.02 \%$. This is comparable with study in Pakistan by Ahmed et al. [20]
Acknowledgements: I am grateful toDr S.M.Patel Head, Department of Pathology, G.C.S medical college hospital and research center.

My warm thanks to Dr Deepak Joshi for his continuous knowledge.

I am highly indebted to my teacher Dr Asha Purohit for her motivation and guidance in preparing manuscript.

I am also thankful to technical staff of histopathology department for their continuous technical support when ever needed.

What this study adds to existing knowledge: Ovarian neoplasms have gradually increased the mortality rate in female genital cancersthis study will help to find incidence of various ovarian tumuors, their age distribution pattern and their morphological subtypes, early diagnosis will reduce the mortality due to ovarian neoplasm.

Findings: Nil; Conflict of Interest: None initiated
Permission from IRB: Yes

\section{References}

1.Juan rosai, Ackerman's surgical pathology $10^{\text {th }}$ edition, volume $2 ; 1553-1635$

2. Shirish S Chandanwale, Rahul Jadhav, Ruby Rao, Piyusha Naragude, Sunita Bhamnikar, Jehan Nizam Ansari. Clinicopathologic Study of Malignant Ovarian Tumors: A Study of Fifty Cases. Med J DY Patil Univ $2017 ; 10: 430-7$.

3. Bhattacharya M, Shinde SD, Purandare VN. A clinicopathological analysis of 270 ovarian tumours. J Postgrad Med. 1980 Apr;26(2):103-7.

4.Susan J. Ramus and Simon A. Gayther. The Contribution of BRCA1 and BRCA2 to Ovarian Cancer Mol Oncol. 2009 Apr; 3(2): 138-150.

5. Schmeler KM, Lynch HT, Chen LM, et al. Prophylactic surgery to reduce the risk of gynecologic cancers in the Lynch syndrome. N Engl J Med. 2006 Jan 19; 354(3):261-9.

6. Isabel Alvarado-Cabrero, Adriana Rodríguez-Gómez, Jorge Castelan-Pedraza, and Raquel Valencia-Cedillo, Metastatic Ovarian Tumors A Clinicopathologic Study of 150 Cases. Analytical and quantitative cytology and histopathology 35(5):241-248 October 2013.

7. Lee SJ, Bae JH, Lee AW, et al. Clinical characteristics of metastatic tumors to the ovaries. J Korean Med Sci. 2009 Feb;24(1):114-9. doi: 10.3346/ jkms. 2009. 24.1.114. Epub 2009 Feb 28. 
8. Shirish S Chandanwale, Rahul Jadhav, Ruby Rao, PiyushaNaragude, Sunita Bhamnikar, Jehan Nizam Ansari.Clinicopathologic Study of Malignant Ovarian Tumors: A Study of Fifty Cases.Oncology (Williston Park).2004May;18(5):645-53,discussion653-4, 656, 658

9. Laury AR, Hornick JL, Perets R, et al. PAX8 reliably distinguishes ovarian serous tumors from malignant mesothelioma. Am J Surg Pathol. 2010 May;34(5):62735. doi: 10.1097/PAS.0b013e3181da7687.

10. Digant Gupta and Christopher G Lis.Role of CA125 in predicting ovarian cancer survival - a review of the epidemiological literature J Ovarian Res. 2009; 2: 13.

11.Russell Vang, Ie-Ming Shih, and Robert J. Kurman, Ovarian low-grade and high-grade serous carcinoma: Pathogenesis, Clinicopathologic and Molecular Biologic Features, and Diagnostic Problems Published in final edited form as: Adv AnatPathol. 2009 Sep; 16 (5): 267-282.

12. Chiesa AG, Deavers MT, Veras E, et al. Ovarian intestinal type mucinous borderline tumors: are we ready for a nomenclature changeInt J Gynecol Pathol. 2010 Mar;29(2):108-12.

13. Cathro HP, Stoler MH. Expression of cytokeratins 7 and 20 in ovarian neoplasia. Am J Clin Pathol. 2002 Jun; 117 (6):944-51.DOI:10.1309/2T1Y-7BB7-DAPEPQ6L

\section{Original Research Article}

14. Hackethal A, Brueggmann D, Bohlmann MK, et al. Squamous-cell carcinoma in mature cystic teratoma of the ovary: systematic review and analysis of published data. Lancet Oncol. 2008 Dec;9(12):1173-80. doi: 10. 1016 / S1470-2045(08)70306-1.

15. S. F. Serov R. E. Scully .Histological typing of ovarian tumours :international histological classification of tumours no.9 world health organization, geneva, switzerland

16. Pilli GS, Suneeta KP, Dhaded AV, et al. Ovarian tumours: a study of 282 cases. J Indian Med Assoc. 2002 Jul;100(7):420, 423-4, 447.

17. Guppy AE, Nathan PD, Rustin GJ. et al. Epithelial ovarian cancer: a review of current management. Clin Oncol (R Coll Radiol). 2005 Sep;17(6):399-411.

18. Yasmin S, Yasmin A, Asif M. Clinicohistological pattern of ovarian tumours in Peshawar region. J Ayub Med Coll Abbottabad. 2008 Oct-Dec;20(4):11-3.

19. Tyagi SP, Maheswari V, Tyagi N, et al. Solid tumours of the ovary. J Indian Med Assoc. 1993 Sep;91 (9): 227-30.

20. Ahmad Z, Kayani N, Hasan SH, et al. Histological pattern of ovarian neoplasma. J Pak Med Assoc. 2000 Dec; 50 (12):416-9.

\section{How to cite this article?}

Rangaliya K, Purohit A, Patel S.M. Retrospective Study of histomorphological spectrum of ovarian tumours in GCS Medical College, Hospital and Research Center, Ahmedabad. Trop J Path Micro 2019;5(1):31-36.doi:10.17511/jopm. 2019.i01.06. 